\title{
Features of Developmental Level of Defense Mechanisms and Adjustment Status of University Students in Japan
}

\author{
Kayo Shichiri*, Masako Shibuya, Kennichi Murayama, Chiyoko Sato, Kyoko Kaminushi, \\ Tomoko Uenoyama, Ichiro Mashima, Takeshi Kuroda, Yoshiki Suzuki \\ Health Administration Center, Niigata University, Niigata, Japan \\ Email: ${ }^{*}$ shichiri@med.niigata-u.ac.jp
}

Received 20 November 2014; revised 27 December 2014; accepted 3 January 2015

Copyright (C) 2015 by authors and Scientific Research Publishing Inc.

This work is licensed under the Creative Commons Attribution International License (CC BY). http://creativecommons.org/licenses/by/4.0/

(c) (i) Open Access

\section{Abstract}

A person with high-level mental defensive functioning exhibits optimal, effective adaptive states when encountering stressors. This may be an important factor in maintaining a sound campus life. Participants were 47 physically and mentally healthy students (average age $19.0 \pm 0.6$ ). We first investigated the developmental level of mental defensive functioning as an indicator of participants' adaptive state at the time of the study. We used the Defensive Functioning Scale proposed in the $4^{\text {th }}$ edition of the Diagnostic and Statistical Manual of Mental Disorders (DSM-IV). We attempted to quantify this scale by summing scores of seven Defense Levels based on individual defense mechanisms. We then measured physical and mental symptoms using the Cornell Medical Index (CMI), and compared the relationships between symptoms and defensive functioning (defensive functioning scale and physical symptoms, defensive functioning scale and mental symptoms, and physical symptoms and mental symptoms). Finally, we compared male and female results. Although there was no statistical difference, males showed higher average scores than females on the Defensive Functioning Scale vs physical/mental symptoms, which may indicate the relative suppression of women that characterizes the social and cultural background in Japan. In addition, there was a relatively high unisex positive correlation between physical symptoms and mental symptoms, which suggests that university health administrative staff need to provide mental as well as physical care to help students manage stress effectively. However, larger, more comparative studies on the social and cultural background are needed to further explore these issues.

\section{Keywords}

Defense Levels and Defensive Functioning, Physical Symptoms, Mental Symptoms, Adaptive

\footnotetext{
${ }^{*}$ Corresponding author.
} 


\section{Introduction}

The increase in mental disorders, particularly following economic crises [1], is a problem in many developed countries. Traditional psychological theory suggests that a person with high-level mental defensive functioning would exhibit an optimal, effective adaptive state when encountering a stressor [2]. This may be an important factor in maintaining a sound student campus life.

We investigated the developmental level of mental defensive functioning as an indicator of participants' adaptive state at the time of the study. We used the Defensive Functioning Scale proposed in “Appendix B” described in the $4^{\text {th }}$ edition of the Diagnostic and Statistical Manual of Mental Disorders (DSM-IV). We attempted to quantify this scale by summing the scores of seven Defense Levels based on individual defense mechanisms. We then examined physical and mental symptoms using the Cornell Medical Index (CMI), and compared relationships between symptoms and defensive functioning. Finally, we compared male and female results.

Our investigation revealed a sex difference in stress management and a unisex positive correlation between physical symptoms and mental symptoms. These findings may contribute to helping university students manage stress effectively.

\section{Methods}

\subsection{Subjects}

Participants were 47 physically and mentally healthy students. Their profile is shown in Table 1. Participants had attended a class in acquiring proficiency in defensive functioning level. Written informed consent was obtained from all subjects and the study was approved by the institutional review board of Niigata University.

\subsection{Instruments}

Defensive Functioning Scale. We used the Defensive Functioning Scale, described in “Appendix B of Criteria sets and axes provided for further study of DSM-IV” to measure participants' level of defensive functioning [3] (Table 2). The scale requires participants to list up to seven defense mechanisms starting with the most prominent; each defense mechanism is grouped under seven Defense Levels (see Table 2). Each participants’ scores on the seven Defense Levels were summed from a possible total of 840 points as follows: High adaptive level (30 points), Mental inhibitions level (25 points), Minor image-distorting level (20 points), Disavowal level (15 points), Major image-distorting level (10 points), Action level (5 points), and Level of defensive dysregulation (0 points). This method of quantification is our original because it is invented by our team.

Cornell Medical Index (CMI). The CMI was developed in the US and is used worldwide for diagnosis and patient care at the bedside [4]-[8]. With the addition of some local questions, this test has been widely used for more than half a century in Japan. It was devised to meet the need to collect a large body of pertinent medical and psychiatric data with minimal time expenditure. It consists of two categories: physical symptoms (including past illness and family history) and mental symptoms (behavior, mood, or feeling). There are 12 sections measuring physical symptoms (A-L) and 6 sections measuring mental symptoms (M-R) as shown in Table 3.

\subsection{Analysis of Adaptive State}

The relationships between defensive functioning and physical symptoms, defensive functioning and mental

Table 1. Profile of participants.

\begin{tabular}{cccc}
\hline Subjects & Male & Female & Total \\
\hline Number (\%) & $28(59.6)$ & $19(40.4)$ & $47(100.0)$ \\
Average age & $19.2 \pm 0.6$ & $18.7 \pm 0.7$ & $19.0 \pm 0.6$ \\
\hline
\end{tabular}


Table 2. Defensive functioning scale defense levels and defense mechanisms (“Appendix B” described in DSM-IV).

\begin{tabular}{llc}
\hline \multicolumn{1}{c}{ Defense levels } & \multicolumn{1}{c}{ Individual defense mechanisms } & Score \\
\hline 1. High adaptive level & $\begin{array}{l}\text { Anticipation, affiliation, altruism, humor, self-assertion, } \\
\text { self-observation, sublimation, suppression }\end{array}$ & 30 \\
2. Mental inhibition level & $\begin{array}{l}\text { Displacement, dissociation, intellectualization, isolation } \\
\text { of affect, reaction formation, repression, undoing }\end{array}$ & 25 \\
3. Minor image-distorting level & Devaluation, idealization, omnipotence & 20 \\
4. Disavowal level & Denial, projection, rationalization & 15 \\
5. Major image-distorting level & $\begin{array}{l}\text { Autistic fantasy, projective identification, splitting } \\
\text { of self-image or image of others }\end{array}$ & 10 \\
6. Action level & $\begin{array}{l}\text { Acting out, apathetic withdrawal, help-rejecting } \\
\text { complaining, passive aggression }\end{array}$ & 5 \\
7. Level of defensive dysregulation & $\begin{array}{l}\text { Delusional projection, psychotic denial, } \\
\text { psychotic distortion }\end{array}$ & 0 \\
\hline
\end{tabular}

Table 3. Cornell Medical Index (CMI).

\begin{tabular}{|c|c|c|c|}
\hline Section & Questions reflecting to & Male & Female \\
\hline & Physical symptoms & & \\
\hline A & Eyes and ears & 10 & 10 \\
\hline $\mathrm{B}$ & Respiratory system & 21 & 21 \\
\hline $\mathrm{C}$ & Cardiovasucular system & 14 & 14 \\
\hline $\mathrm{D}$ & Digestive tract & 28 & 28 \\
\hline $\mathrm{E}$ & Musculoskelectal system & 10 & 10 \\
\hline $\mathrm{F}$ & Skin & 9 & 9 \\
\hline G & Nervous system & 19 & 19 \\
\hline $\mathrm{H}$ & Genitourinary system & 11 & 13 \\
\hline I & Fatigability & 7 & 7 \\
\hline $\mathrm{J}$ & Frequency of illness & 9 & 9 \\
\hline $\mathrm{K}$ & Miscellaneous disease & 15 & 15 \\
\hline \multirow[t]{3}{*}{$\mathrm{L}$} & Habits & 7 & 7 \\
\hline & Total & 160 & 162 \\
\hline & Mental symptoms & & \\
\hline M & Mood and feeling patterns & 12 & 12 \\
\hline $\mathrm{N}$ & Inadequacy & 6 & 6 \\
\hline $\mathrm{O}$ & Depression & 9 & 9 \\
\hline $\mathrm{P}$ & Anxiety & 6 & 6 \\
\hline $\mathrm{Q}$ & Sensitivity & 9 & 9 \\
\hline \multirow[t]{2}{*}{$\mathrm{R}$} & Anger & 9 & 9 \\
\hline & Total & 51 & 51 \\
\hline
\end{tabular}

symptoms, and physical symptoms and mental symptoms were examined to investigate the developmental level of defensive functioning and adaptive state. Regression analyses were conducted using statistical software Statcel 2 (OMS Publishing, Saitama, Japan), which is written in Visual Basic for Applications. The Mann-Whitney 
U test was performed using IBM SPSS Statistics for Windows version 20.0 (Armonk, NY: IBM Corp.). Means ( \pm standard deviations) were calculated to compare male and female groups. All statistical tests were two-tailed and statistical significance was defined as $\mathrm{P}<0.05$.

\section{Results}

\subsection{Average Scores for Defensive Functioning, Physical Symptoms, and Mental Symptoms}

Means and standard deviations for scores on the defensive functioning scale, physical symptoms, and mental symptoms are shown in Table 4.

\subsection{Relationship between Defensive Functioning and Physical and Mental Symptoms}

The relationships between defensive functioning and physical symptoms, and between defensive functioning and mental symptoms, were examined. Males scored higher than females on defensive functioning and physical symptoms, although the differences were not statistically significant $(\mathrm{P}=0.91, \mathrm{P}=0.51$, respectively). This may be because of the considerable individual variability in these scores.

For males, there was a positive correlation between defensive functioning and physical symptoms, and between defensive functioning and mental symptoms; however, these relationships were negative for females (Figure 1(a), Figure 1(b)). There was also a notable difference in the average of physical symptoms scores. Females scored higher than males by 2 points on section $\mathrm{H}$ of the CMI (genitourinary system). However, the overall average CMI score for males was higher than that of females (15.5 \pm 7.8 compared to $14.8 \pm 6.1$ ).

\subsection{Relationship between Physical Symptoms and Mental Symptoms: Maintaining the Integrity of the Specifications}

Correlations between physical symptoms and mental symptoms were positive and relatively high for both males and females ( $\left[\mathrm{R}^{2}\right]: 0.74[0.5485]$ and 0.77 [0.5969]) (Figure 1(c)).

\section{Discussion}

\subsection{Defense Mechanisms}

Defense mechanisms are automatic psychological processes that protect the individual against anxiety and from the awareness of internal or external dangers or stressors. Individuals are often unaware of these processes as they operate. Defense mechanisms mediate the individual's reaction to emotional conflicts and to internal and external stressors. Individual defense mechanisms are divided conceptually and empirically into related groups that are referred to as Defense Levels [3].

The results of this study showed that participants' developmental level of mental defensive functioning was quite sound (males [683.8 \pm 140.3$] / 810$, females [653.9 \pm 85.3$] / 810$ ). This suggests that the personality structure has almost completely developed by 18 - 20 years old.

\subsection{Male and Female Differences}

Although the differences were not statistically significant, it was of interest that males' average scores on the Defensive Functioning Scale, physical symptoms and mental symptoms were higher than females'. This may be a result of the social and cultural background in Japan, which has led to the suppression of women's social status. For modern Japanese women, physical and mental patience is considered a virtue [9].

Table 4. Comparison between males and females (Means and SDs).

\begin{tabular}{lccc}
\hline \multicolumn{1}{c}{ Scores } & Male & Female & P value \\
\hline Defensive functioning scale & $683.8 \pm 140.3$ & $653.9 \pm 85.3$ & 0.91 \\
Physical symptoms score & $15.5 \pm 7.8$ & $14.8 \pm 8.1$ & 0.51 \\
Mental symptoms score & $9.9 \pm 7.3$ & $8.5 \pm 7.3$ & 0.09 \\
\hline
\end{tabular}



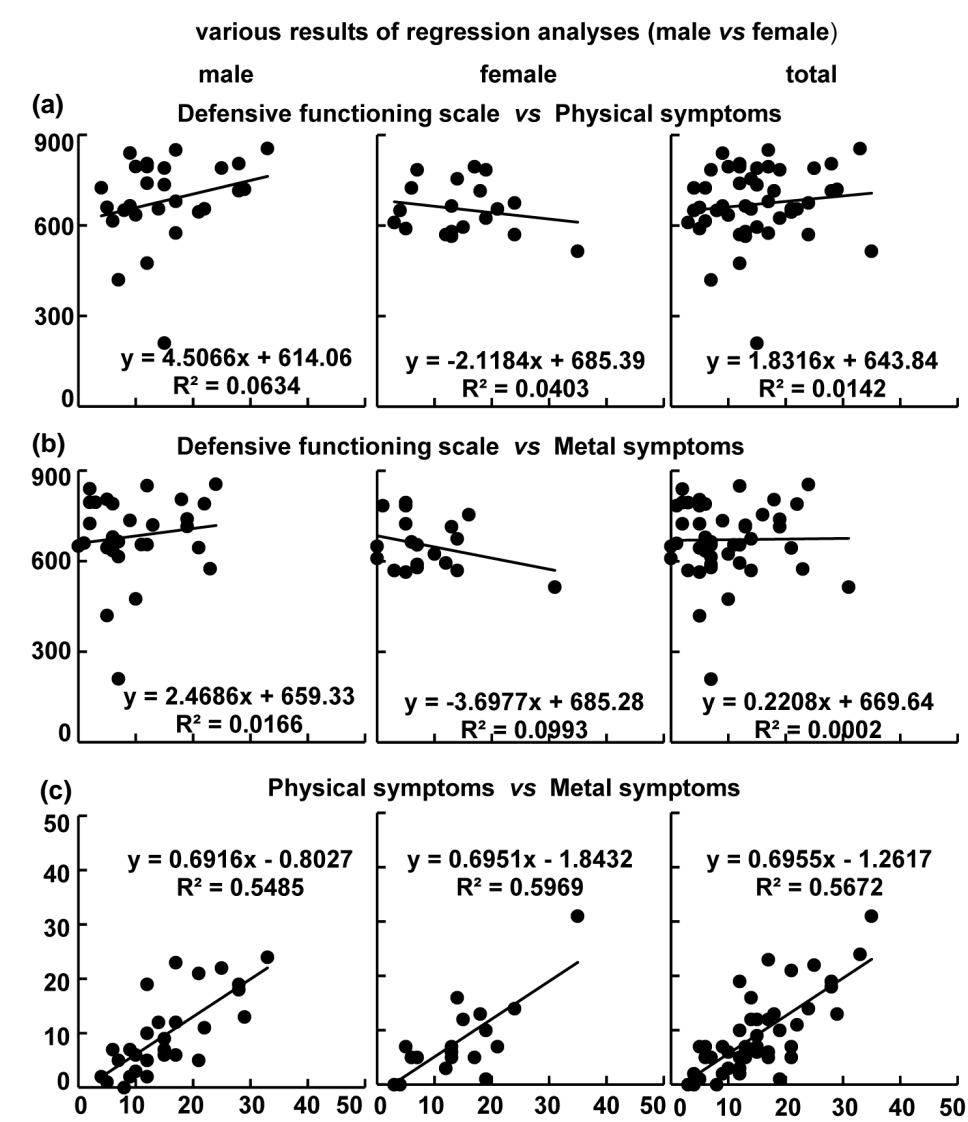

Figure 1. Various results of regression analyses were conducted (male vs female). The left panel, the middle and the right panel showed all subjects, male and female respectively. (a) Defensive functioning scale and Physical symptoms; (b) Defensive functioning scale and Mental symptoms; (c) Physical symptoms and Mental symptoms.

A pertinent example is the ratio of female administrative service workers above the level of division chief in Japan. This is a mere $11.1 \%$, whereas the same figures in America and France are 43.1\% and 39.4\%, respectively [10]. Even in modern times, young females may be unduly influenced by this traditional attitude and may consciously_or unconsciously_suppress their thoughts and feelings even when experiencing physical or mental stress.

\subsection{Relationship between Physical and Mental Symptoms}

For both males and females, there was a relatively high correlation between physical symptoms and mental symptoms; this psychosomatic correlation suggests an adaptive response. Therefore, university health administrative staff need to provide both physical and mental care to help students manage stress effectively. However, larger, comparative studies exploring the social and cultural background of other countries are needed to add support to these conclusions.

\section{Acknowledgements}

The authors thank all student volunteers who participated in this study. Special thanks to Dr Mayumi Watanabe of Dept. of Medical Informatics, Niigata University Medical and Dental Hospital, for preparation of the manuscript.

\section{References}

[1] World Health Organization Regional Office for Europe (2011) Impact of Economic Crises on Mental Health. 
http://www.euro.who.int/_data/assets/pdf_file/0008/134999/e94837.pdf

[2] Freud, A. (1936) Das Ich und Abwehrmechanismen. Internationaler Phychoanalytischer Verlag.

[3] American Psychiatric Association (1994) Diagnostic and Statistical Manual of Mental Disorders: DSM-IV. 4th Edition, American Psychiatric Association, Washington DC.

[4] Brodman, K., Erdmann Jr., A.J., Lorge, I., Wolff, H.G. and Broadbent, T.H. (1951) The Cornell Medical Index-Health Questionnaire. II. as a diagnostic instrument. The Journal of American Medical Association, 145, 152-157. http://dx.doi.org/10.1001/jama.1951.02920210024006

[5] Brodman, K., Deutschberger, J., Erdmann Jr., A.J., Lorge, I. and Wolff, H.G. (1954) Prediction of Adequacy for Military Service: Use of the Cornell Medical Index-Health Questionnaire. US Armed Forces Medical Journal, 5, 18021808.

[6] Brodman, K., Erdmann Jr., A.J., Lorge, I., Gershenson, C.P. and Wolff, H.G. (1952) The Cornell Medical IndexHealth Questionnaire. III. The Evaluation of Emotional Disturbances. Journal of Clinical Psychology, 8, 119-124. http://dx.doi.org/10.1002/1097-4679(195204)8:2<119::AID-JCLP2270080204>3.0.CO;2-V

[7] Brodman, K., Erdmann Jr., A.J., Lorge, I., Gershenson, C.P. and Wolff, H.G. (1952) The Cornell Medical IndexHealth Questionnaire IV. The Recognition of Emotional Disturbances in a General Hospital. Journal of Clinical Psychology, 8, 289-293. http://dx.doi.org/10.1002/1097-4679(195207)8:3<289::AID-JCLP2270080312>3.0.CO;2-B

[8] Erdmann Jr., A.J., Brodman, K., Lorge, I. and Wolff, H.G. (1952) Cornell Medical Index-Health Questionnaire. V. Outpatient Admitting Department of a General Hospital. The Journal of American Medical Association, 7, 550-551. http://dx.doi.org/10.1001/jama.1952.02930230024007

[9] Yukawa, T. and Ishida, S. (2005) An Examination into Measurement for Changes of Gender Cognition. Nara University Proceedings, 33, 81-93.

[10] Japan Institute for Labour Policy and Training (2013) Databook of International Labour Statistics 2013. http://www.jil.go.jp/kokunai/statistics/databook/2013/documents/Databook2013.pdf 
Scientific Research Publishing (SCIRP) is one of the largest Open Access journal publishers. It is currently publishing more than 200 open access, online, peer-reviewed journals covering a wide range of academic disciplines. SCIRP serves the worldwide academic communities and contributes to the progress and application of science with its publication.

Other selected journals from SCIRP are listed as below. Submit your manuscript to us via either submit@scirp.org or Online Submission Portal.
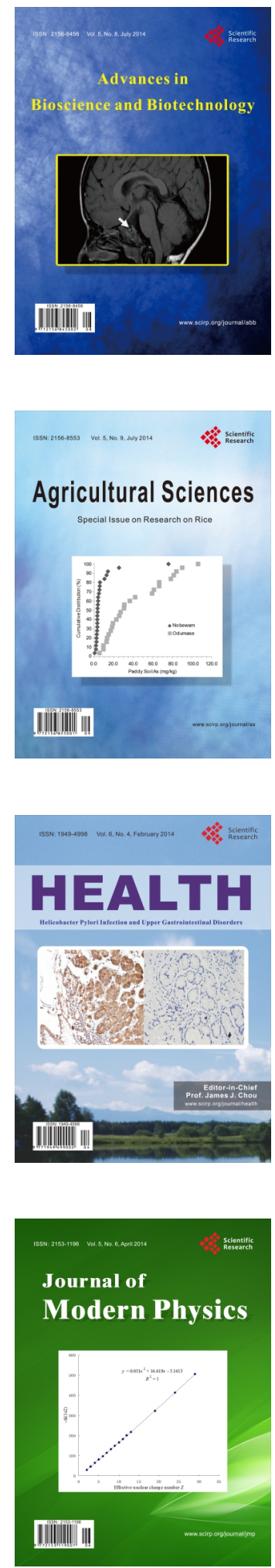
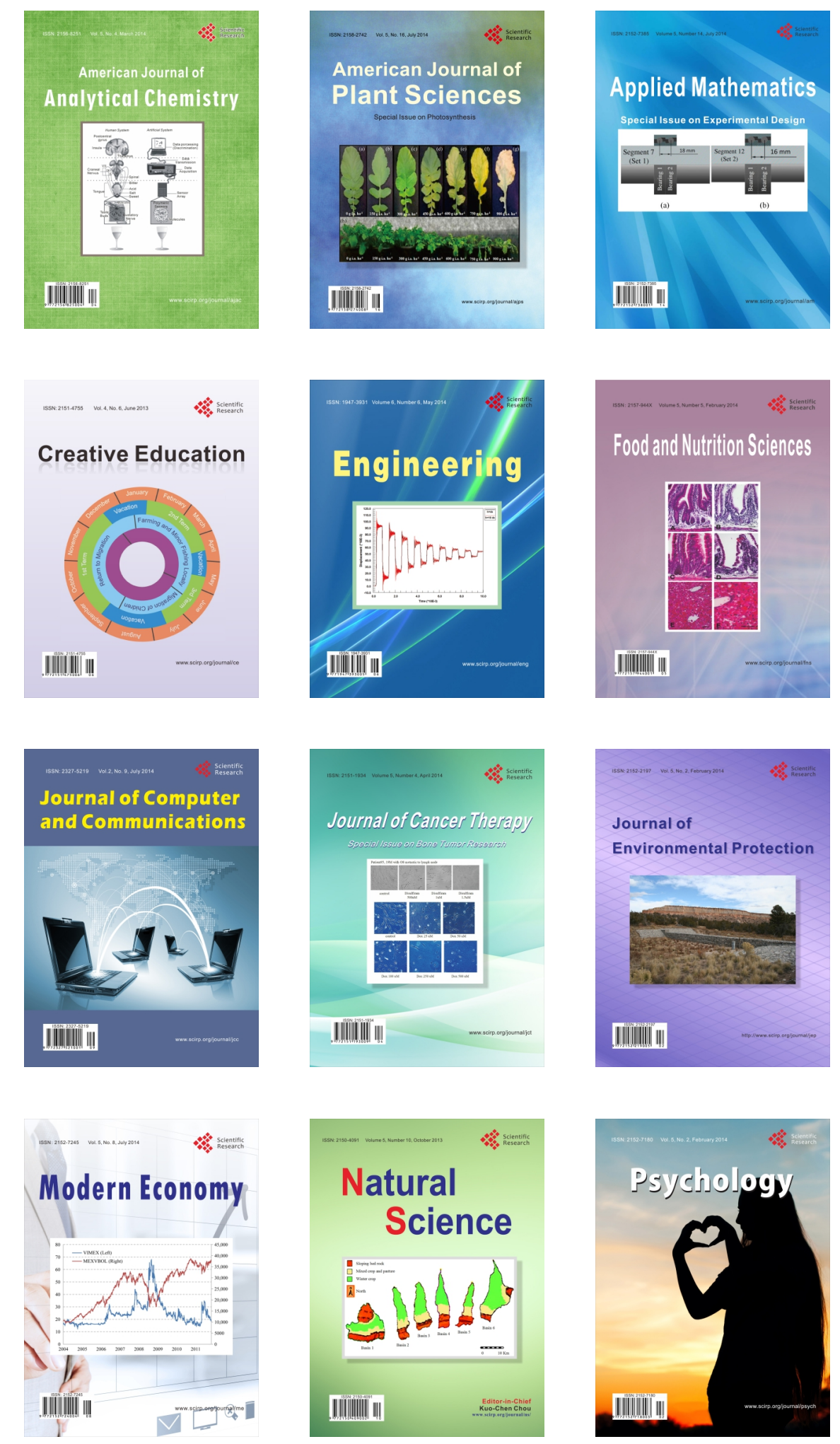